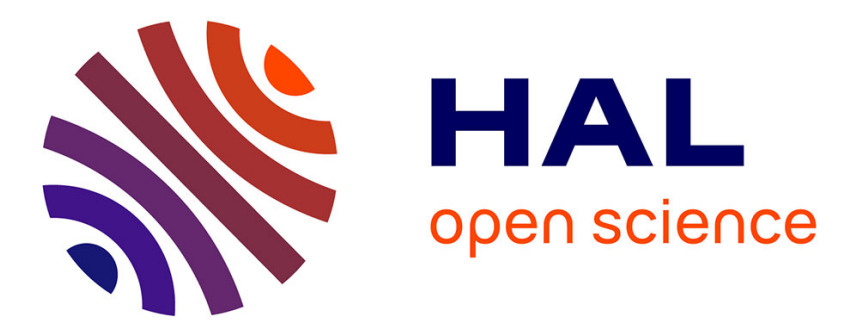

\title{
Structure, Magnetism and Colossal Magnetoresistance Behavior in A2Mn2O7 Pyrochlores (A = Dy-Lu, Y, Sc, In or $\mathrm{Tl}$ )
}

\author{
M. Subramanian, J. Greedan, N. Raju, A. Ramirez, A. Sleight
}

\section{- To cite this version:}

M. Subramanian, J. Greedan, N. Raju, A. Ramirez, A. Sleight. Structure, Magnetism and Colossal Magnetoresistance Behavior in A2Mn2O7 Pyrochlores (A = Dy-Lu, Y, Sc, In or Tl). Journal de Physique IV Proceedings, 1997, 07 (C1), pp.C1-625-C1-628. 10.1051/jp4:19971258 jpa-00254966

\section{HAL Id: jpa-00254966 https://hal.science/jpa-00254966}

Submitted on 1 Jan 1997

HAL is a multi-disciplinary open access archive for the deposit and dissemination of scientific research documents, whether they are published or not. The documents may come from teaching and research institutions in France or abroad, or from public or private research centers.
L'archive ouverte pluridisciplinaire HAL, est destinée au dépôt et à la diffusion de documents scientifiques de niveau recherche, publiés ou non, émanant des établissements d'enseignement et de recherche français ou étrangers, des laboratoires publics ou privés. 


\title{
Structure, Magnetism and Colossal Magnetoresistance Behavior in $\mathrm{A}_{2} \mathrm{Mn}_{2} \mathrm{O}_{7}$ Pyrochlores (A = Dy-Lu, Y, Sc, In or Tl)
}

\author{
M.A. Subramanian, J.E. Greedan*, N.P. Raju*, A.P. Ramirez** and A.W. Sleight*** \\ Dupont Central Research and Development, Experimental Station, Wilmington, DE 19880-0328, U.S.A. \\ * Institute for Materials Research, McMaster University, Hamilton, L85 4M1, Canada \\ ** Bell Laboratories, Lucent Technologies, 600 Mountain Avenue, Murray Hill, NJ 07974, U.S.A. \\ *** Department of Chemistry, Oregon State University, Corvallis, OR 97331, U.S.A.
}

\begin{abstract}
This paper presents a bird's eye view of the structural, electrical and magnetic properties of $\mathrm{A}_{2} \mathrm{Mn}_{2} \mathrm{O}_{7}(\mathrm{~A}=$ rare earth, $\mathrm{Y}, \mathrm{Sc}, \mathrm{In}, \mathrm{Tl}$ ) phases crystallizing in pyrochlore-related structure. Electrical measurements indicate the compounds containing rare earth, $\mathrm{Y}, \mathrm{Sc}$ or In are insulators whereas $\mathrm{Tl}_{2} \mathrm{Mn}_{2} \mathrm{O}_{7}$ is highly conducting. All the compounds show spontaneous magnetization at low temperatures indicating ferromagnetic transitions. Detailed ac and $\mathrm{dc}$ susceptibility as well as neutron diffraction studies do not provide any evidence for long-range order in $\mathrm{A}_{2} \mathrm{Mn}_{2} \mathrm{O}_{7}$ phases where $\mathrm{A}$ is a rare earth, $\mathrm{Y}$ or Sc, but suggest a spin-glass like behavior. However, powder neutron diffraction and smallangle neutron scattering investigations substantiate the long-range magnetic ordering in $\mathrm{Tl}_{2} \mathrm{Mn}_{2} \mathrm{O}_{7}$, which is also now known to exhibit colossal magnetoresistance (CMR) behavior. Structural analysis of this phase shows no deviations from ideal stoichiometry and gives an Mn-O distance of $\sim 1.90 \AA$, significantly shorter than the $\mathrm{Mn}$-O distances in the range 1.94 to $2.00 \AA$ observed in phases based on $\mathrm{LaMnO}_{3}$ perovskites which show CMR. The above observation indicates that oxidation state of $\mathrm{Mn}$ in $\mathrm{Tl}_{2} \mathrm{Mn}_{2} \mathrm{O}_{7}$ should be very close to $4+$ and has neither mixed valency for a doubleexchange magnetic interaction nor a Jahn-Teller cation such as $\mathrm{Mn}^{3+}$. Both were thought to play an essential role in CMR materials. We propose that $\mathrm{CMR}$ in $\mathrm{Tl}_{2} \mathrm{Mn}_{2} \mathrm{O}_{7}$ is based on magnetic ordering driven by superexchange and strong spin fluctuation scattering above $\mathrm{T}_{\mathrm{C}}$.
\end{abstract}

\section{INTRODUCTION}

The recent interest in colossal magnetoresistance $(\mathrm{CMR})$ in ferromagnetic perovskite-based doped lanthanum manganites has rekindled interest in studying transition metal oxides exhibiting mixed valency a feature essential for double-exchange interaction. As a part of our systematic studies of transition metal compounds crystallizing in pyrochlore-related structure (which has a general formula, $\mathrm{A}_{2} \mathrm{M}_{2} \mathrm{O}_{7}$ ), in recent years, we have been investigating the structural, electrical and magnetic properties of oxides of the type $\mathrm{A}_{2} \mathrm{Mn}_{2} \mathrm{O}_{7}(\mathrm{~A}=$ rare earth, Y, Sc, In or Tl) (1-7). These compounds crystallize in the facecentered-cubic structure with a space group $\mathrm{Fd} 3 \mathrm{~m}$. The pyrochlore structure of $\mathrm{A}_{2} \mathrm{Mn}_{2} \mathrm{O}_{7}$ (or more appropriately $\mathrm{A}_{2} \mathrm{Mn}_{2} \mathrm{O}_{6} \mathrm{O}^{\prime}$ ) is based on a network of corner-sharing $\mathrm{MnO}_{6}$ octahedra just as in perovskite $\mathrm{CaMnO}_{3}$ (Fig 1). The A atoms are located in the center of the hexagonal rings formed by oxygens $(\mathrm{O}$, located at the $48 \mathrm{f}$ positions) with two more oxygens $\left(\mathrm{O}^{\prime}\right.$, at the $8 \mathrm{~b}$ positions) located above and below the ring. Hence, the $\mathrm{A}$ atom environment can be considered as distorted cube. The pyrochlore structure can also be viewed as two interpenetrating networks : one with the formula $\mathrm{MnO}_{3}$ and the other with the formula $\mathrm{A}_{2} \mathrm{O}^{\prime}$. Because the $\mathrm{MnO}_{3}$ network forms the backbone of the structure, vacancies can occur only on the $\mathrm{A}$ and $\mathrm{O}^{\prime}$ sites [8]. However, unlike in perovskite structure, the $\mathrm{Mn}$ atoms (as well as $\mathrm{A}$ atoms) in these compounds are located in the corners of a tetrahedral units which share corners to form infinite, intersecting chains. Such an arrangement leads to a very high degree of magnetic frustration if the nearest-neighbor interactions are antiferromagnetic. In this paper, we summarize the structural, electrical and magnetic properties of these phases. In addition, our recent results on the structural analysis of the ferromagnetic $\mathrm{Tl}_{2} \mathrm{Mn}_{2}^{4+} \mathrm{O}_{7}$ pyrochlore phase exhibiting $\mathrm{CMR}$ behavior are also included.

\section{EXPERIMENTAL}

All the phases require high pressures for the synthesis and is primarily due to the small size of $\mathrm{Mn}^{4+}$ when compared to $\mathrm{A}^{3+}$ cations for the stabilization of the pyrochlore lattice. $\mathrm{A}_{2} \mathrm{Mn}_{2} \mathrm{O}_{7}$ compounds where $\mathrm{A}=\mathrm{Dy}$-Lu were synthesized under $3 \mathrm{kbar}$ pressure whereas the phases with $\mathrm{A}=\mathrm{Sc}$, In or $\mathrm{Tl}$ could be prepared only under $58 \mathrm{kbar}$ pressure. The details of the experimental procedures used in the synthesis, single-crystal $\mathrm{x}$-ray and powder neutron diffraction, electrical and magnetic studies are described elsewhere [1-3, 7]. 


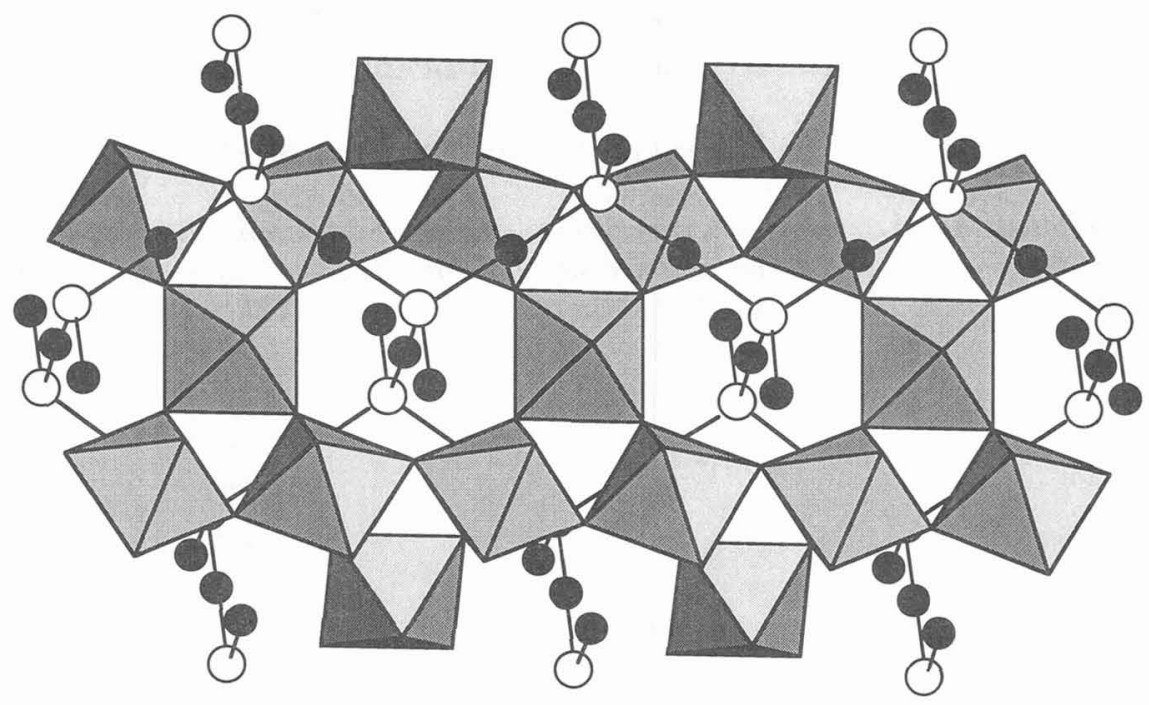

Figure 1: Schematic view of the pyrochlore structure of $\mathrm{A}_{2} \mathrm{Mn}_{2} \mathrm{O}_{7}$ (octahedra : $\mathrm{MnO}_{6}$; open circles: $\mathrm{O}^{\prime}$; filled circles: $\mathrm{A}$ )

\section{RESULTS AND DISCUSSION}

\section{1 $\mathrm{A}_{2} \mathrm{Mn}_{2} \mathrm{O}_{7}(\mathrm{~A}=\mathrm{Dy}-\mathrm{Lu}, \mathrm{Y}, \mathrm{Sc})$ pyrochlores}

All the phases crystallize in cubic symmetry $(F d 3 m)$ and the lattice constants are listed in Table I. Structural determinations of $\mathrm{A}_{2} \mathrm{Mn}_{2} \mathrm{O}_{7}$ phases by single crystal $X$-ray diffraction $(A=E r, Y)$, powder neutron diffraction $(A=H o, Y b)$ and powder $X$ ray diffraction $(A=S c)$ refinements confirm the pyrochlore structure for all the phases and there is no evidence for any site disorder (mixing among cations) or for significant vacancy concentrations on the oxygen sites. Hence, all appear to be stoichiometric pyrochlores with a general formula $\mathrm{A}_{2}^{3+} \mathrm{Mn}_{2}^{4+} \mathrm{O}_{7}$. Electrical measurements indicate all are insulators with room temperature resistivities in the range $10^{6}$ to $10^{8} \Omega \mathrm{cm}$ and activation energy 0.4 to $0.5 \mathrm{eV}$ [1]. The results on the magnetic properties are also listed in Table I. All the compounds in this series show similar susceptibility data and obeying a Curie-Weiss law at higher temperatures. The $\theta_{c}$ value for all the phases are large and positive indicating strong ferromagnetic exchange interactions between Mn moments. At low temperatures all the phases show a sharp increase in the susceptibility with decreasing temperature again indicting the possibility for a long-range ferromagnetic order. The $T_{c}$ values given in Table I are derived from such data. However, low field dc susceptibility data for these phases $(A=S c, Y, H o, Y b$ and $\mathrm{Lu})$ exhibit clear field-cooled (FC), zero-field-cooled (ZFC) irreversibilities below "Tc" with a broad maxima $[2,4,5,6]$. Ac susceptibility results also show a similar behavior and the position of the maxima is frequency dependent $[2,5]$. Heat capacity studies down to $2 \mathrm{~K}$ for $\mathrm{Y}_{2} \mathrm{Mn}_{2} \mathrm{O}_{7}$ show no sharp anomaly and hence no evidence for long-range magnetic order. In addition low temperature neutron diffraction and scattering data of $\mathrm{Y}_{2} \mathrm{Mn}_{2} \mathrm{O}_{7}$ seems to indicate the presence of both near neighbor antiferromagnetic and ferromagnetic (second and third neighbor) short range correlations. These materials show many complex magnetic properties in common with spin glasses in spite of the fact that there is no evidence for chemical site disorder [2,4]. As mentioned earlier, the $\mathrm{Mn}$ atoms in $\mathrm{A}_{2} \mathrm{Mn}_{2} \mathrm{O}_{7}$ occupy the corners of a tetrahedra. Spins at two points of the tetrahedron may couple in an antiparallel fashion, but it then impossible for the remaining two atoms of the tetrahedron to align their spins antiparallel to the first two. This high degree of frustration seems to be responsible for the above observed unusual as well as complex magnetic behavior. It appears that there exists a strong competition between ferromagnetism and frustrated antiferromagnetism, with superexchange dominating the magnetic interaction.

\section{$3.2 \mathrm{Tl}_{2} \mathrm{Mn}_{2} \mathrm{O}_{7}$ and $\mathrm{In}_{2} \mathrm{Mn}_{2} \mathrm{O}_{7}$ pyrochlores}

Both compounds crystallize in cubic pyrochlore structure and crystallographic data are included in Table I. Magnetic data for $\mathrm{Tl}_{2} \mathrm{Mn}_{2} \mathrm{O}_{7}$ indicate the compound is ferromagnetic and the relevant data are also given in Table I. However, unlike $\mathrm{A}_{2} \mathrm{Mn}_{2} \mathrm{O}_{7}$ ( $\mathrm{A}=\mathrm{Dy}-\mathrm{Lu}, \mathrm{Y}$ or $\mathrm{Sc}$ ) phases, there is no appreciable difference between $\mathrm{FC}$ and ZFC susceptibilities [3]. In addition, SANS clearly show evidence for the long-range magnetic order which is indicative of strong ferromagnetic interactions between Mn moments [3]. Electrical measurements show the compound is a good conductor with a room temperature resistivity in the range 0.1 to $0.01 \Omega \mathrm{cm}$. This is again in contrast to the insulating behavior exhibited by $\mathrm{A}_{2} \mathrm{Mn}_{2} \mathrm{O}_{7}$ phases $(\mathrm{A}=\mathrm{Dy}-\mathrm{Lu}, \mathrm{Y}$ or $\mathrm{Sc})$. The resistivity as a function of temperature for $\mathrm{Tl}_{2} \mathrm{Mn}_{2} \mathrm{O}_{7}$ shows a very sharp drop in resistivity at the magnetic ordering temperature $[3,9]$. 
Table I. Crystallographic and Magnetic Properties of $\mathrm{A}_{2} \mathrm{Mn}_{2} \mathrm{O}_{7}$ Pyrochlores

\begin{tabular}{|c|c|c|cc|c|c||}
\hline $\mathbf{A}$ & $\mathbf{a}[\mathbf{A}]$ & $\mathbf{x}$ parameter & \multicolumn{2}{|c|}{$\mu_{\mathbf{e f f}}\left(\mu_{\mathbf{B})^{\mathbf{2}}}\right.$} & $\theta_{\mathbf{c}}(\mathbf{k})$ & $\mathbf{T}_{\mathbf{c}}(\mathbf{K})$ \\
\hline \hline $\mathrm{Dy}$ & 9.929 & - & 14.4 & 15.9 & $+33(2)$ & $40(5)$ \\
\hline $\mathrm{Ho}$ & 9.907 & $0.3277(2)$ & 14.4 & 15.9 & $+33(2)$ & $37(5)$ \\
\hline $\mathrm{Er}$ & 9.875 & $0.3281(8)$ & 13.3 & 14.6 & $+40(5)$ & $35(5)$ \\
\hline $\mathrm{Tm}$ & 9.847 & - & 10.4 & 12.0 & $+56(8)$ & $30(5)$ \\
\hline $\mathrm{Yb}$ & 9.838 & $0.3285(3)$ & 7.6 & 8.3 & $+41(3)$ & $40(5)$ \\
\hline $\mathrm{Lu}$ & 9.815 & - & 4.9 & 5.4 & $+70(10)$ & $23(5)$ \\
\hline $\mathrm{Y}$ & 9.902 & $0.3274(8)$ & 5.4 & 5.4 & $+50(10)$ & $20(5)$ \\
\hline $\mathrm{Sc}$ & 9.929 & - & 5.1 & 5.4 & $+77(3)$ & $17(2)$ \\
\hline $\mathrm{In}$ & 9.717 & - & 5.3 & 5.4 & $+150(10)$ & $120(5)$ \\
\hline $\mathrm{Tl}$ & 9.890 & $0.3254(8)$ & 5.4 & 5.6 & $+160(10)$ & $121(5)$ \\
\hline
\end{tabular}

1 Atomic positions are, $\mathrm{A}: 16 \mathrm{~d}(1 / 2,1 / 2,1 / 2) ; \mathrm{Mn}: 16 \mathrm{c}(0,0,0), \mathrm{O}^{\prime}: 8 \mathrm{~b}(3 / 8,3 / 8,3 / 8)$; and $\mathrm{O}: 48 \mathrm{f}(\mathrm{x}, 1 / 8,1 / 8)$

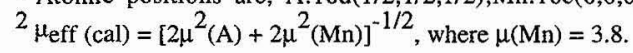

Although $\mathrm{In}_{2} \mathrm{Mn}_{2} \mathrm{O}_{7}$ pyrochlore also show high ferromagnetic Curie temperature (Table I), the FC and ZFC susceptibility data seem to indicate a spin-glass like behavior similar to one observed in $\mathrm{A}_{2} \mathrm{Mn}_{2} \mathrm{O}_{7}$ ( $\mathrm{A}=\mathrm{Dy}-\mathrm{Lu}, \mathrm{Y}, \mathrm{Sc}$ ). Nevertheless, preliminary SANS data as well as magnetic saturation behavior seem to support for the presense of a long-range order. This phase is a semiconductor with a room temperature resistivity $\left(\sim 10^{3} \Omega \mathrm{cm}\right.$ ) falling in-between insulating $\mathrm{A}_{2} \mathrm{Mn} \mathrm{n}_{2} \mathrm{O}_{7}$ (A $=\mathrm{Dy}_{-}$ $\mathrm{Lu}, \mathrm{Y}, \mathrm{Sc}$ ) and highly conducting $\mathrm{Tl}_{2} \mathrm{Mn}_{2} \mathrm{O}_{7}[3]$.

\subsection{Colossal magnetoresistance behavior of $\mathrm{Tl}_{2} \mathrm{Mn}_{2} \mathrm{O}_{7}$}

As mentioned earlier, the $\mathrm{Tl}_{2} \mathrm{Mn}_{2} \mathrm{O}_{7}$ show a strong coupling between magnetic and electrical resistivity measurements in the form of sharp decrease by factors of $10-10^{2}$ near $T_{c}$. This behavior is very similar to the one observed in mixed valent ferromagnetic $\mathrm{La}_{1-\mathrm{x}}^{3+} \mathrm{M}_{\mathrm{X}}^{2+} \mathrm{Mn}_{2-\mathrm{x}}^{3+} \mathrm{Mn}_{\mathrm{X}}^{4+} \mathrm{O}_{3}\left(\mathrm{M}^{2+}=\mathrm{Ca}, \mathrm{Sr}, \mathrm{Ba}\right.$ or $\left.\mathrm{Pb}\right)$ perovskites and are known to show the colossal magnetoeresistance effect [10]. These compounds have attracted much attention due to their possible use in magnetic storage media. Ferromagnetism in these phases is due to the double-exchange interactions through $\mathrm{Mn}^{3+-} \mathrm{O}-\mathrm{Mn}^{4+}[11]$. Very recently, $\mathrm{CMR}$ effect comparable to perovskites also has been reported for $\mathrm{Tl}_{2} \mathrm{Mn}_{2} \mathrm{O}_{7}$ [12]. Our structural analysis with powder neutron diffraction and single-crystal X-ray diffraction data of a sample of $\mathrm{Tl}_{2} \mathrm{Mn}_{2} \mathrm{O}_{7}$ exhibiting CMR (Fig. 2) show the compound is stoichiometric with no detectable vacancies at the $\mathrm{Tl}$ or $\mathrm{O}^{\prime}$ sites [7]. Furthermore, the observed $\mathrm{Mn}-\mathrm{O}$ distance of $1.90 \AA$ is significantly shorter than $\mathrm{Mn}-\mathrm{O}$ distances observed in perovskites containing $\mathrm{Mn}^{3+}$ and $\mathrm{Mn}^{4+}$. It is clear that there is no evidence for the presence of mixed valency nor a presence of Jahn-Teller cation such as $\mathrm{Mn}^{3+}$ in $\mathrm{Tl}_{2} \mathrm{Mn}_{2} \mathrm{O}_{7}$, both were thought to play an essential role in CMR materials. In perovskites, the CMR occurs over a range of 20 to $40 \%$ hole doping (with respect to $\mathrm{Mn}$ ) resulting from substitution of divalent alkaline earth for trivalent lanthanum.

The high conductivity observed in $\mathrm{Tl}_{2} \mathrm{Mn}_{2} \mathrm{O}_{7}$ is most likely due to the overlapping of the $\mathrm{Tl} 6 s$ band with $\mathrm{Mn} 3 d$ band. In chemical terms, this overlap means internal reduction and oxidation of $\mathrm{Tl}^{3+}$ of $\mathrm{Mn}^{4+}$ respectively. This is reflected in the bond distances refined from single crystal X-ray and neutron diffraction data. Despite the small Mn-O distance, the lattice parameter of $\mathrm{Tl}_{2} \mathrm{Mn}_{2} \mathrm{O}_{7}$ is larger than expected from ionic radius of $\mathrm{A}^{3+}$ versus unit cell plot for $\mathrm{A}_{2} \mathrm{Mn}_{2} \mathrm{O}_{7}$ pyrochlores $[3,7]$. In addition, Hall effect data on $\mathrm{Tl}_{2} \mathrm{Mn}_{2} \mathrm{O}_{7}$ indicate a small number of high mobility n-type carriers [12]. This would not be expected from a Mn $3 \mathrm{~d}$ band but could result from a small number of carriers in the $\mathrm{Tl} 6 \mathrm{~s}$ band. These carriers could be produced by $\mathrm{Tl}_{2-\mathrm{x}}^{3+} \mathrm{Tl}_{\mathrm{x}}^{2+} \mathrm{Mn}_{2-\mathrm{x}}^{4+} \mathrm{Mn}_{\mathrm{x}}^{5+} \mathrm{O}_{7}$ or $\mathrm{Tl}_{2-\mathrm{y}}^{3+} \mathrm{Tl}_{\mathrm{y}}^{2+} \mathrm{Mn}_{2}^{4+} \mathrm{O}_{7-\mathrm{y} / 2}$. The value of $\mathrm{x}$ or $\mathrm{y}$ would need to be only about 0.005 to explain the Hall data, and this would be consistent with our measured stoichiometry as well as above mentioned larger unit cell parameter for $\mathrm{Tl}_{2} \mathrm{Mn}_{2} \mathrm{O}_{7}$.

Although ferromagnetic pyrochlore compound $\mathrm{Tl}_{2} \mathrm{Mn}_{2} \mathrm{O}_{7}$ bears more than superficial similarity to the CMR manganese oxide perovskite compounds, the above results underscore the difference between the two families. We propose that CMR effect in $\mathrm{Tl}_{2} \mathrm{Mn}_{2} \mathrm{O}_{7}$ is based on magnetic ordering driven by superexchange and strong spin fluctuation scattering above $\mathrm{T}_{\mathrm{c}}$. This realization of a new route to CMR opens up a range of possibilities for designing new materials with specific properties for eventual use in magnetic storage media applications. 


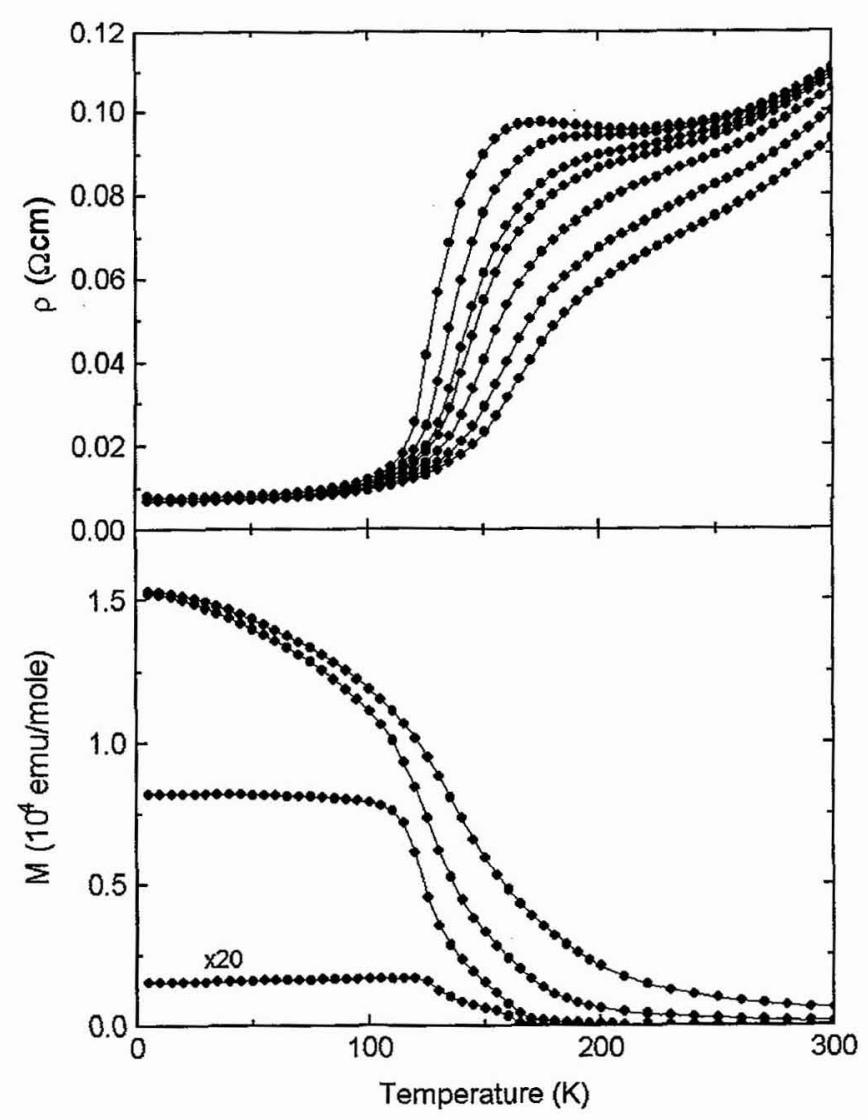

Figure 2: Temperature dependence of the resistivity (upper panel) and the magnetization (lower panel) for $\mathrm{Tl}_{2} \mathrm{Mn}_{2} \mathrm{O}_{7} . \mathrm{The}$ resistivity data are for 0 (top), $0.1,1,2,4,6$ and 8 (bottom) $\mathrm{T}$. The magnetization data are for 0.001 (bottom), $0.1,1$ and 4 (top) T.

\section{Acknowledgments}

We thank T. G. Calvarese and M. L. Plummer for help with high pressure synthesis. The authors also thank B. H. Toby, G. H. Kwei and W. J. Marshall for crystallographic data on $\mathrm{Tl}_{2} \mathrm{Mn}_{2} \mathrm{O}_{7}$.

\section{References}

1. Subramanian M. A., Torardi C.C., Johnson D. C., Pannetier J., Sleight A. W., J. Solid State Chem. 72 (1988) 24.

2. Reimers J. N., Greedan J. E., Cremer C. R., Gmelin E., Subramanian M. A., Phys. Rev. B43 (1991) 3387.

3. Raju N. P., Greedan J. E., Subramanian M. A., Phys. Rev. B49 (1994) 1086.

4. Raju N. P., Greedan J. E., Maignan A., Simon Ch., Pederson J. S, Niraimathi A. M., Gmelin. A., Subramanian M. A., Phys. Rev. B, submitted.

5. Greedan J. E., Avelar J., Subramanian M. A., Solid State Commun. 82 (1992) 797.

6. Greedan J. E., Raju N. P., Subramanian M. A., Solid State Commun., in press.

7. Subramanian M. A., Toby B. H., Ramirez A. P., Marshall W. J., Sleight., Kwei G. H., Science, in press.

8. Subramanian M. A., and Sleight A. W., in Handbook on the Physics and Chemistry of Rare Earths 10 eds. Gschneider Jr. K. A., Eyring L., (Elsevier, Amsterdam,1993), p. 225; Subramanian M. A., Aravamudan G., Subba Rao G. V., Prog. Solid State Chem. 15 (1983) 55.

9. Fujinaka H., Ninomura N., Koizumi M., Miymoto Y., Kume S., Mat. Res. Bull., 14 (1979) 1133.

10. Jin S., et al., Science 264 (1994) 413; Shiffer P., Ramirez A. P., Bao W., Cheong S.-W., Phys. Rev. Lett. 75 (1995) 3336.

11. Zener C., Phys. Rev. 82, 403 (1951); Anderson P. W., Hasegawa H., Phys. Rev. 100 (1955) 675; de Gennes P.-G., Phys. Rev. 118, (1960) 141.

12. Shimakawa Y., Kubo Y., Manako T., Nature 379, (1996) 53. 